\title{
El eslabón perdido: la gestión del suelo en las políticas de urbanización bajo los Planes Federales de vivienda en Avellaneda y Ciudad de Buenos Aires
}

\author{
The missing link: Land management in urbanization policies under the Federal Housing Plans in Avellaneda and the City \\ of Buenos Aires
}

Denise Brikman *, Mercedes Najman *, Florencia Aramburu * y María Mercedes Di Virgilio*.

Recibido: 13 de julio de 2018

Aceptado: 27 de mayo de 2019

\section{Resumen}

En el marco de la salida de la crisis social, económica y política del año 2001, se desarrollaron en Argentina un conjunto de programas habitacionales que habilitaron procesos de urbanización de asentamientos informales con implementaciones y resultados bien diversos. Las características del suelo y los mecanismos para su gestión no fueron incorporadas en los diseños, lo que habilitó estrategias diversas que facilitaron (o no) la implementación de las políticas. Este artículo propone caracterizar los distintos modelos de gestión de suelo desarrollados e identificar si condicionaron las posibilidades de su implementación. Se analizan, mediante un abordaje cualitativo, cuatro casos de intervención ubicados en zonas centrales del Área Metropolitana de Buenos Aires - Avellaneda y la Ciudad de Buenos Aires- que reflejan instrumentos de gestión y resultados diversos. El análisis demuestra que ciertas características intrínsecamente territoriales -como la localización, la propiedad del suelo, la escala de los barrios- en relación con los actores participantes y la definición de los destinatarios, condicionaron el desarrollo de los instrumentos de gestión del suelo y posibilitaron distintos resultados.

Palabras clave: asentamientos informales, gestión del suelo, políticas de urbanización.

\begin{abstract}
In the framework of the exit of the social, economic and political crisis of the year 2001, a set of housing programs were developed in Argentina that enabled processes of urbanization of informal settlements with very diverse implementations and results. The characteristics of the land and the mechanisms for its management were not incorporated into the designs, which enabled diverse strategies that facilitated (or not) the implementation of the policies. This article proposes to characterize the different land management models developed and to identify if they conditioned the possibilities of their implementation. Four intervention cases located in central areas of the Metropolitan Area of Buenos Aires -Avellaneda and the City of Buenos Aires- that reflect management instruments and diverse results are analyzed through a qualitative approach. The analysis shows that certain intrinsically territorial characteristics -such as location, land ownership, the scale of neighborhoods- in relation to the participating actors and the definition of the recipients, conditioned the development of land management instruments and made possible different results.
\end{abstract}

Keywords: informal settlements, land management, urban policies.

\footnotetext{
* Filiación: CONICET - Instituto de Investigaciones Gino Germani, Universidad de Buenos Aires, Buenos Aires, Argentina.

Contacto: denisebrikman@gmail.com, mercedesnajman@gmail.com, floraramburu8190@gmail.com, mercedes.divirgilio@gmail.com
}

Este artículo se desarrolló con base en un trabajo previo presentado por las autoras en el Seminario Latinoamérica de Teoría Política sobre Asentamientos Populares, organizado por Info-Hábitat y Universidad Nacional de General Sarmiento. 19, 20 y 21 de abril, Buenos Aires. Las autoras agradecen los comentarios recibidos durante el Seminario, así como los de los revisores anónimos que contribuyeron a mejorar la calidad del texto.

Cómo citar: Brikman, M., Najman, M., Aramburu, F. y Di Virgilio, M. (2019). El eslabón perdido. La gestión del suelo en las políticas de urbanización bajo los Planes Federales de vivienda en Avellaneda y Ciudad de Buenos Aires. Revista de Urbanismo, 40, 1-20. https://doi.org/10.5354/0717-5051.2018.50567 


\section{Introducción}

A partir del año 2003, la política habitacional, tras décadas de ausencia, se reincorporó a la agenda pública argentina. Desde el Poder Ejecutivo nacional, la política de vivienda, mediante los Planes Federales $(P F)^{1}$, fue definida como un objetivo prioritario al considerarla un engranaje fundamental para la recuperación económica y el Área Metropolitana de Buenos Aires (AMBA) se situó como un territorio central de intervención ${ }^{2}$.

La asignación presupuestaria de los PF contemplaba la construcción de vivienda nueva pero paradójicamente no tenía en cuenta la adquisición de suelo para su emplazamiento. En este sentido, su diseño -elaborado por el Poder Ejecutivo Nacional- no consideró los costos de adquisición del suelo ni desarrolló lineamientos para el acceso al mismo. Esta situación, impuso a los gobiernos locales la necesidad de desarrollar diversos mecanismos para adquirir suelo urbano en la metrópolis, en un marco de escasez de predios disponibles y aptos para la construcción (Clichevsky, 1999; Ostuni, 2007).

Este artículo propone identificar y caracterizar los diversos modelos de gestión del suelo que fueron desarrollados, aun sin ser contemplados formalmente en los diseños originales de las políticas habitacionales de urbanización de asentamientos informales. A partir de un análisis comparativo de casos se busca evidenciar que diversos factores -territoriales e institucionalesincidieron sobre el desarrollo de las diferentes

1 Los PF tuvieron diversas operatorias: Programa Federal de Construcción de Viviendas y el Programa Federal de Mejoramiento de Viviendas "Mejor Vivir", a los que en el 2005 se le sumó el Subprograma Federal de Urbanización de Villas y Asentamientos Precarios. El Programa de Emergencia Habitacional, surgido en el 2003, posteriormente se incorporó también a la batería de Programas. Los diferentes contextos sociales, políticos e institucionales influyeron en los modos en que el mismo fue desarrollándose e hicieron que cada municipio opte por qué programas efectivizar. La ejecución de cada Programa produjo una gran heterogeneidad de los mecanismos, herramientas y modos de implementación (Ostuni, 2012)

2 La asignación presupuestaria para los cupos de vivienda a construir por el PF se basó en los datos del déficit habitacional que arrojó el Censo 2001. Por este motivo, al AMBA se le asignó el 30,7\% de las soluciones habitacionales, en respuesta a los 888.149 hogares en situación deficitaria que concentraba dicho territorio. Específicamente, la CABA obtuvo el 5,2\% y el Conurbano Bonaerense el 25,5\% del total país (Chiara, Virgilio y Aramburu, 2017). estrategias de gestión del suelo desplegadas por los gobiernos locales en cada caso de estudio, posibilitando resultados diversos de la intervención.

\section{Marco teórico}

Entendemos a las políticas de urbanización como aquellas intervenciones orientadas a revertir las condiciones de informalidad dominial, es decir la tenencia de la tierra, y/o las deficiencias urbanoambientales. Pueden contemplar acciones de mejoramiento y/o producción de vivienda nueva (Clichevsky, 2003). Fernandes (2008) incorpora a esta definición a las intervenciones orientadas a la inclusión social o de generación de empleo. Las políticas de urbanización varían según los objetivos, costos, visibilidad, apoyo de los organismos internacionales, la acción de los actores sociales, etc.

En la política habitacional argentina ha sido frecuente el mecanismo de disociación entre la vivienda y su soporte (Cuenya, 2016), dejando por fuera de los diseños de las políticas los efectos de la localización y sus externalidades urbanas. Yujnovsky (1984) sostiene que la orientación hacia la reducción del déficit cuantitativo de vivienda excluyó aspectos vinculados al déficit cualitativo y al hábitat de los diseños, ocultando el vínculo entre la vivienda, suelo urbano y su inserción en la ciudad. De este modo, la efectividad de las políticas habitacionales no puede escindirse de las intervenciones sobre el suelo urbano (Hardoy, 1970).

La actualidad de los planteos de Yujnovsky y Hardoy se expresa en diversos estudios que, en las últimas décadas, evalúan la calidad de los programas habitacionales contemporáneos en la Argentina y en la región (Bois Morales, 2008; Chiara, Virgilio y Aramburu, 2017; Cuenya, 2016; Del Río y Duarte, 2012; Pírez, 2014; Rodríguez y Surgranyes, 2005). Éstos dan cuenta de la persistente disociación entre la producción de unidades de vivienda y la política de suelo. Esta escisión, limita la capacidad de la política pública para facilitar el efectivo acceso de la población con necesidades habitacionales a la vivienda social. En este marco, tal y como señala Calderón, en la región:

[S]e ha intentado resolver esta desconexión [...] por medio de la intervención pública, sujeta al péndulo entre políticas inclinadas a la defensa 
irrestricta de la propiedad privada, y otras más bien dispuestas a aplicar cargas y beneficios a la propiedad y desarrollar mecanismos de captura de plusvalía urbana. Entre las diversas alternativas se han desplegado instrumentos como los "bancos de tierras", ajustes de tierras, la promoción de programas "mixtos" de vivienda para clase media y sectores de menores ingresos. Según las particularidades de cada país, estos instrumentos han sido aceptados (aunque implementados con dificultad) o rechazados. Mientras que Colombia es un ejemplo de lo primero, Chile y Perú lo son de lo segundo. (2015, p.32)

Recientemente Blanco, Fretes Cibils y Muñoz (Blanco et al., 2016) compilaron y analizaron un conjunto de experiencias desarrolladas en diferentes países de la región, así como el contexto legal, administrativo y de política pública en el que se inscriben. El estudio pone en evidencia que los gobiernos subnacionales se encuentran en un proceso progresivo de desarrollo y aplicación de mecanismos de captura de plusvalías. ${ }^{3}$ A pesar de estos avances, la política de vivienda social continúa convirtiendo a los precios del suelo "no en un componente del costo de la vivienda sino en parte de las ganancias generadas por los proyectos inmobiliarios: una renta capitalizada" (Calderón, 2015, p.32).

Las limitaciones que experimentan las políticas de gestión del suelo en la región parecen obedecer a su carácter mediador. Se trata de políticas intermediarias en tanto:

[S] us objetivos no se definen por sí mismos, por ejemplo, por la disminución de precios. El éxito de una política de suelo urbano se define respecto a objetivos que son definidos en otro ámbitos (políticas de vivienda, especialmente de vivienda social, políticas medio ambiente, equipamiento público) (Renard, 2000, p.44).

De este modo, la existencia de un sistema legal y fiscal que regula los derechos de propiedad desde una

\footnotetext{
${ }^{3}$ Este proceso se inicia a mediados de la década de 1980 y reconoce como hitos el Plan Director Estratégico de São Paulo y sus operaciones interligadas (1985) y la Ley de Reforma Urbana en Colombia y sus instrumentos de gestión del suelo (1989).
}

perspectiva conservadora en el caso Argentino, tal y como sostiene Cuenya (2016), este sistema se expresa en la Constitución Nacional, el Código Civil y las interpretaciones particulares que se hace de estos textos legales cuando se aplica la ley y se formulan las políticas urbanas- y el carácter mediador de las intervenciones sobre el manejo del suelo, contribuyen a invisibilizar su importancia en la implementación de las políticas habitacionales.

En el caso argentino, ante el déficit de suelo urbano libre para la implementación del Plan Federal de Construcción de Vivienda, se incorporaron dos modalidades de intervención. En el año 2005, se desarrolla el Subprograma Federal de Urbanización de Villas y Asentamientos Precarios (SUVAP), orientado a la dotación de servicios, apertura de calles y construcción de vivienda en asentamientos informales, en predios ya ocupados y habitados. Estas intervenciones proponían consolidar a la población en el sitio que habitaban previamente y contemplaban la relocalización de aquellas familias que se encontraban en sectores urbanos de alto riesgo ambiental. Asimismo, en la Provincia de Buenos Aires, el Instituto Provincial de Vivienda (IPV) generó la operatoria denominada Tierra y Proyecto Urbano (TPU). En ella, las empresas constructoras debían presentar proyectos integrales que incluyesen la provisión del suelo. Estas modalidades habilitaron el desarrollo de diferentes instrumentos de gestión del suelo urbano dentro de un mercado que, ante la ausencia de mecanismos de regulación, impuso al sector público serias limitaciones en el acceso a la tierra urbana. En este trabajo desandamos los modos en que los gobiernos locales sortearon esta problemática para la implementación de las políticas habitacionales, considerando las particularidades de cada territorio de intervención.

Entendemos como política de gestión del suelo a toda intervención orientada a la adquisición (compra, dación de pago, instrumentos tributarios, expropiación, etc.) y/o refuncionalización (cambios de usos, englobamiento de parcelas, etc.) de terrenos $\mathrm{y} / \mathrm{o}$ inmuebles vacantes por parte de organismos estatales, pudiendo implicar en el proceso la utilización de múltiples instrumentos y herramientas. El objetivo de identificar y caracterizar la gestión para la obtención de suelo urbano desarrollada en cada caso de estudio implica contrastar las 
características institucionales (los instrumentos de gestión empleados, la disponibilidad de herramientas para habilitar suelo urbano, el entramado de actores intervinientes) y territoriales de los asentamientos en los que se intervino, los cuales imprimen elementos particulares en los proyectos de urbanización.

\section{Casos de Estudio: Descripción y cartografía}

El trabajo analiza las experiencias de gestión del suelo en cuatro casos de estudio (Figura 1) que presentan diferentes abordajes e instrumentos en la implementación de políticas habitacionales para población de asentamientos informales. Dos de los casos seleccionados se ubican en la Ciudad Autónoma de Buenos Aires (CABA), donde la implementación del SUVAP se realizó mediante el proyecto Sueños Compartidos. Por un lado, el asentamiento informal Ciudad Oculta -Villa 15- originado en la década del 1940 y en la actualidad se presenta como una de las cinco villas más grandes de la CABA. En su historia se registran diversas intervenciones que procuraron - con distintos, aunque reducidos, niveles de éxito- desarrollar proyectos habitacionales y de urbanización. En el período de análisis, se logró ejecutar parcialmente el programa a piloto Construcción e integración social Misión Sueños Compartidos, mediante el PFCV, que tenía como objetivo la completa urbanización de Villa 15. Sin embargo, estos proyectos de urbanización quedaron históricamente truncos, en parte, debido a los obstáculos generados por la multiplicidad de propietarios de la tierra.

Abordamos como segundo caso de estudio al proyecto habitacional que dio origen al Conjunto Urbano Barrio Padre Mugica (CUBPM), construido también bajo el programa Sueños Compartidos en el marco del SUVAP, mediante una operatoria específica junto a organizaciones de la sociedad civil, en este caso, la Fundación Madres de Plaza de mayo ${ }^{4}$. Se trató de un proyecto de 780 viviendas, que contempló inicialmente espacios comunitarios tales como comedores, escuelas y plazas. Si bien en sus inicios, estaba destinado a población de diferentes asentamientos informales ubicados en los alrededores del terreno adquirido y a la población de un asentamiento ubicado en Villa Soldati que había sufrido un incendio, finalmente fue destinado por vías de judicialización a población de diversos asentamientos informales de la Ciudad de Buenos Aires. En este sentido, el CUBPM introduce un caso de construcción de vivienda social que implicó procesos de relocalización.

Por último, indagamos sobre dos casos localizados en la Ciudad de Avellaneda, Provincia de Buenos Aires. Villa Tranquila, una de las principales villas de dicha localidad, originada a principios del siglo $X X$, se ubica en el área central en una zona de fuerte preeminencia industrial. Allí el Municipio combinó la implementación del SUVAP y el Programa de Mejoramiento Barrial (PROMEBA), en el marco del Plan de Urbanización del barrio. Este caso ilustra la articulación de modalidades de gestión del suelo en zonas centrales para construir vivienda social en los mismos territorios a reurbanizar. La implementación del plan estuvo divido en pequeños proyectos, que tenían como objetivo la construcción de 701 viviendas en diferentes etapas y con distintas localizaciones al interior de Villa Tranquila.

El cuarto caso de estudio, el Barrio Los Cardales, está ubicado en la localidad de Wilde, Ciudad de Avellaneda. Constituye un ejemplo de política habitacional para población de asentamientos informales construida fuera de los barrios de intervención. Se trata de un conjunto de 158 viviendas construido en la periferia del área urbana del Municipio sin contemplar un programa de urbanización.

\footnotetext{
${ }^{4}$ La asociación Madres de Plaza de Mayo, icono de la lucha por los derechos humanos en el país, surge durante la última dictadura cívicomilitar argentina bajo el reclamo de aparición con vida de los detenidos desaparecidos. Su trayectoria a lo largo de los años involucra además múltiples proyectos con el propósito de continuar el legado político de sus hijos.
} 


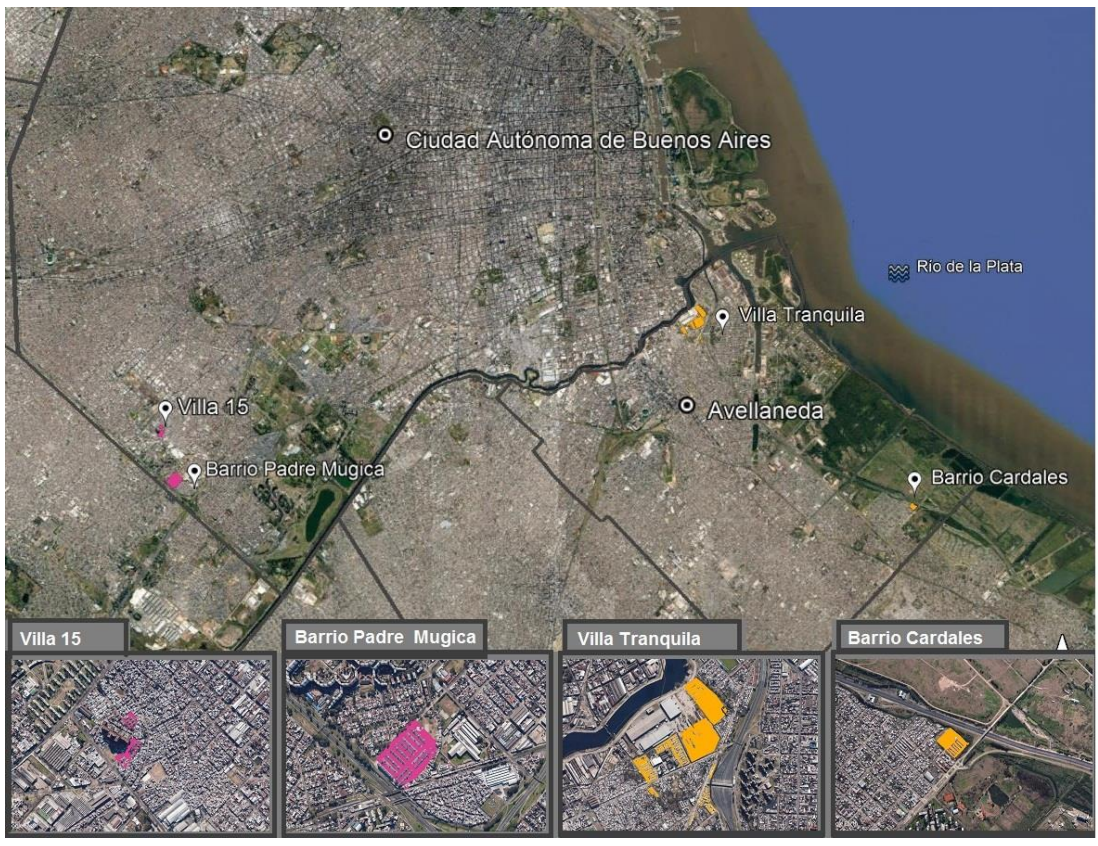

Figura 1. Localización proyectos del Programa Misión Sueños Compartidos, Villa 15, Barrio Padre Mugica, Villa Tranquila y Barrio Cardales. Año 2018. Fuente: intervención sobre imagen obtenida desde Google Earth.

\section{Aspectos metodológicos}

Con base en el análisis de cuatro casos de estudio, el trabajo pone en dialogo tres dimensiones de análisis: las características de la gestión del suelo en las políticas de vivienda del SUVAP, las acciones desarrolladas por las instituciones estatales y las características de los territorios en donde se implementan dichas políticas. Se propone analizar la incidencia de estas dos últimas dimensiones en las particularidades que toman los procesos de gestión del suelo. Para ellos se desarrolla un estudio comparado mediante una estrategia metodológica cualitativa.

El estudio comparado se fundamenta principalmente en el objetivo de comprender las similitudes y diferencias de los procesos de implementación del SUVAP $y$, específicamente, la gestión del suelo para los casos de estudio seleccionados. La técnica de la comparación permite mediante la confrontación identificar los atributos similares y los diferentes (Sartori, 1994). La comparación requiere contrastar elementos que poseen características comunes y otras no compartidas (Sartori, 1994). En este caso, hemos seleccionado cuatros barrios donde el SUVAP se implementó y donde se han desarrollado procesos de gestión del suelo como parte necesaria para desarrollar los proyectos de urbanización -características comunes. Asimismo, dos de los barrios seleccionados (Villa 15 y C.H. Padre Mugica) se localizan en la zona sur de la Ciudad de Buenos Aires y los otros dos (Villa Tranquila y Los cardales) en un Municipio de la primera conurbación de la Provincia. Es decir, poseen localizaciones diferenciales dentro del Área Metropolitana de Buenos Aires (AMBA), dimensión que entendemos también influye tanto en la configuración de los propios territorios como en los modos de intervención estatal. A la vez, si bien el Gobierno Nacional en ambos casos posee competencias, en los barrios ubicados en la Ciudad también interviene el Gobierno local con sus organismos competentes y lo mismo sucede para el caso de Avellaneda con las instituciones de la Provincia y del propio municipio. Por último, si bien en todos los casos analizamos proyectos de construcción de vivienda nueva que de algún modo están vinculados a procesos de urbanización -en el mismo barrio o en otros-, los proyectos son disimiles.

La comparación se apoya en el desarrollo de una estrategia metodológica cualitativa a partir de analizar datos primarios obtenidos con base en entrevistas a informantes clave y secundarios -documentales y estadísticos. Los informantes fueron funcionarios públicos encargados de la aplicación del SUVAP en cada uno de los territorios seleccionados, que podían brindar información relevante para la investigación. Se utilizó el 
criterio de saturación teórica para definir las necesidades del material a recolectar, realizándose entrevistas hasta alcanzar la certeza de que nuevos relatos no brindarían información novedosa. Dichas entrevistas buscaron reconstruir desde la perspectiva de los actores las características de los proyectos desarrollados y los diversos instrumentos implementados en la gestión del suelo y las características de dicha elección e implementación. Asimismo, permitieron profundizar en las características institucionales a partir de reconstruir el entramado actoral interviniente y la definición de los destinatarios. Los datos primarios se complementaron con una serie de documentos secundarios, principalmente documentales, como decretos, información pública sobre los proyectos realizados, evaluaciones y auditorias, entre otros.
El análisis se apoyó en la identificación de una serie de dimensiones (Tabla 1 ) para los diversos casos de estudio seleccionados buscando realizar un abordaje comparativo, que permitió esbozar conclusiones sobre una política que presenta puntos en común pero también disparidades según el territorio de aplicación:

- Las características de la gestión del suelo y de los proyectos planteados para cada uno de los casos de estudio.

- Las características y acciones de las instituciones estatales a partir de los actores intervinientes y la definición de los destinatarios.

- Las características territoriales, es decir, la localización del barrio, la propiedad del suelo y la escala barrial de intervención. 


\section{Tabla 1}

Casos y dimensiones en perspectiva comparada.

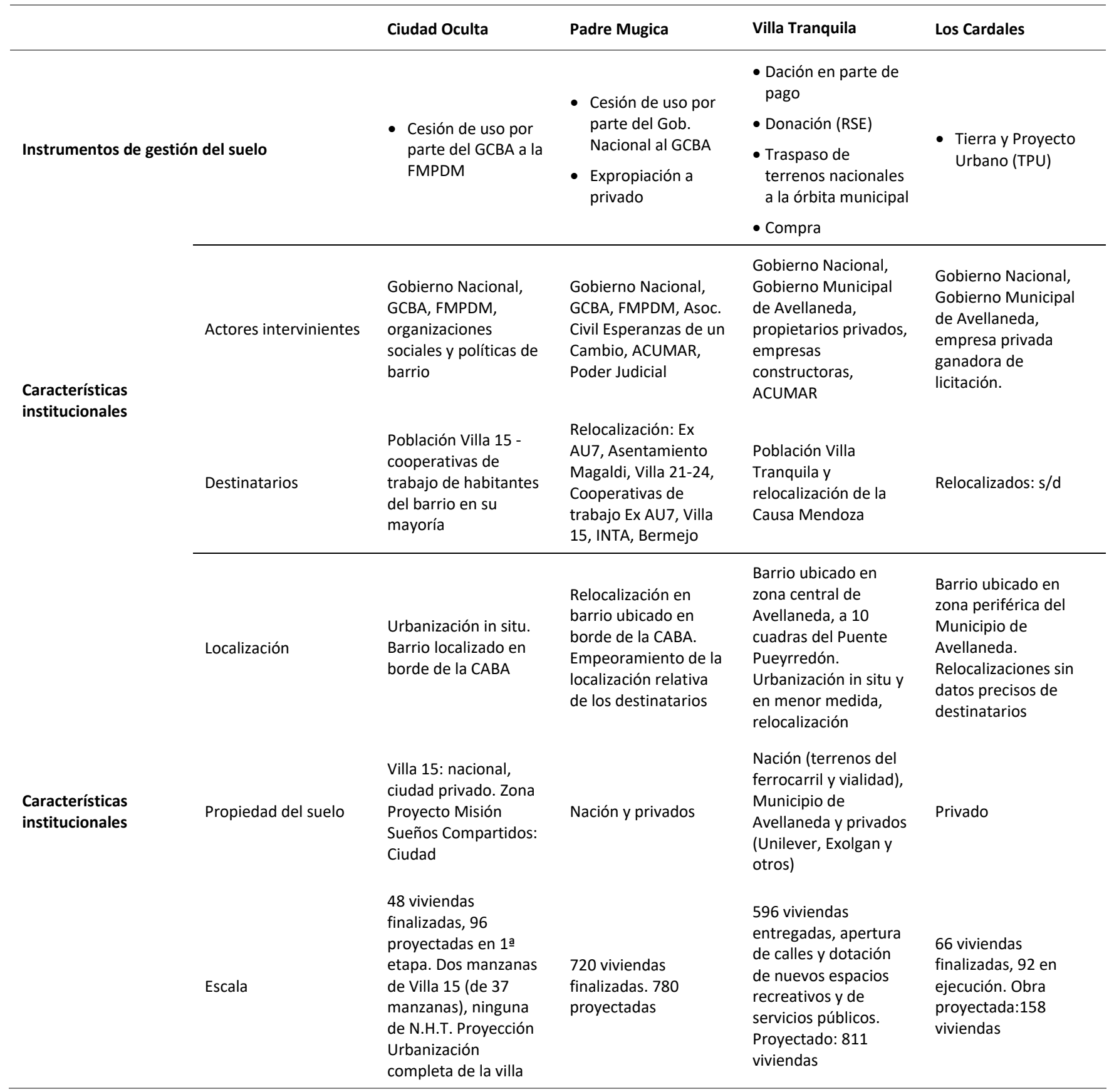

Fuente: Elaboración propia.

\section{Análisis de resultados}

\section{Implementación del SUVAP en la CABA.}

Villa 15 y el CUBPM se ubican en el barrio de Lugano, en la Comuna 8 de la CABA (Figura 2). La comuna 8 contiene diversas tipologías de hábitat (complejos habitacionales de distintas épocas, villas, asentamientos y ciudad formal, entre otros), concentrando la mayor cantidad de villas, asentamientos y complejos habitacionales de la Ciudad. A su vez, se observan grandes extensiones de tierra pública vacante, parques, clubs y depósitos, entre otros, que rompen con la trama urbana (Di Virgilio, et al., 2011). 

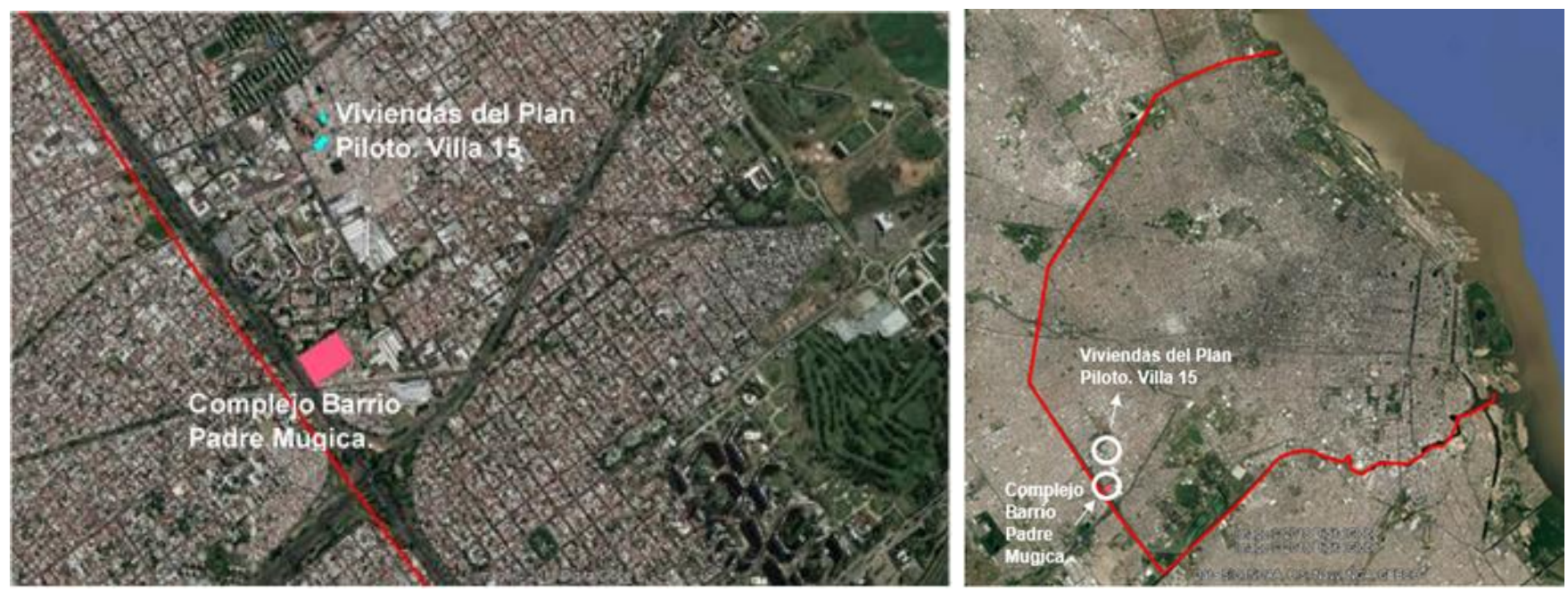

Figura 2: Localización proyectos del Programa Misión Sueños Compartidos, Villa 15 y Barrio Padre Mugica. Fuente: intervención sobre imagen obtenida desde Google Earth.

En sintonía con la tradicional elección de esta zona de la ciudad para la construcción de vivienda social, las ejecuciones del SUVAP en la CABA se concentraron principalmente en la Comuna 8 pese a caracterizarse por un fuerte déficits en equipamiento e infraestructura (Brikman, 2017; Najman, 2018).

En estos dos casos de estudio, el Subprograma permitió el financiamiento para el desarrollo de dos proyectos de urbanización mediante el Programa Misión Sueños Compartidos. Este programa nace en octubre de 2006 como un plan piloto de capacitación en construcción de vivienda, mediante un convenio entre la Universidad Popular Madres de Plaza de Mayo (FMDP) y el Ministerio de Derechos Humanos y Sociales de la CABA. En el transcurso de la última década, el programa se implementó en diferentes lugares del país.

El programa desplegó un abordaje complejo de las problemáticas socio-habitacionales entendiendo a la construcción de vivienda como un sistema general de urbanización. Las construcciones se llevaron a cabo mediante cooperativas de trabajo impulsadas desde el programa, lo cual respondía al objetivo de facilitar la integración social de población excluida y altamente vulnerable mediante la actividad laboral. En el año 2012, como consecuencia de una denuncia de corrupción que comprometió a la Fundación Madres de Plaza de Mayo, el programa fue interrumpido. En algunos de los proyectos en marcha - tal fue el caso del CUBPM-, los derechos y obligaciones asumidos por la Fundación fueron transferidos a empresas constructoras que asumieron las responsabilidades de ejecución de las obras pendientes y muchos de los componentes centrales de los proyectos fueron abandonados. El programa de urbanización de Villa 15 , que se proponía iniciar con la construcción de 96 viviendas para luego regularizar y mejorar urbanísticamente la totalidad del barrio, culminó en la construcción de únicamente 48 viviendas. En el caso del CUBPM, la construcción de las viviendas continuó pero abandonando la contratación de cooperativas y paralizando la construcción de espacios comunes como escuelas o comedores.

\section{El caso de Ciudad Oculta}

La selección de Villa 15 como prueba del Plan Piloto de Capacitación en Construcción de Viviendas del Programa Sueños Compartidos, se explica por necesidades territoriales vinculadas a un incendio que dejó sin vivienda a varias familias. Asimismo, las vinculaciones políticas de algunos referentes del barrio con funcionarios del Gobierno Nacional facilitaron el conocimiento y selección del caso.

El proyecto tenía como objetivo la completa urbanización de la villa y el desarrollo de un proceso de inclusión socioterritorial, impulsado tanto por el mejoramiento urbano como por la reactivación económica a través de las nuevas fuentes de trabajo. Sin embargo, debido a la interrupción imprevista del 
programa, muchos de estos elementos quedaron a medio camino.

Según la Auditoría General de la Nación (2013), en Ciudad Oculta se firmaron distintos convenios, que proyectaban en una primera etapa, la construcción de 96 viviendas y la mejora de 72. Sin embargo, sólo se finalizaron 48 viviendas y 24 quedaron inconclusas. Se realizaron dos proyectos: uno lindante al Elefante Blanco (edificios rojos) - donde se priorizó la reubicación de las familias damnificadas por el incendio y habitantes de las inmediaciones del edificio Elefante Blanco- y otro ubicado en un terreno vacío que guardaba el presidente del N.H.T Av. Del Trabajo para realizar un proyecto de vivienda (edificios grises) (Figura 3 ).

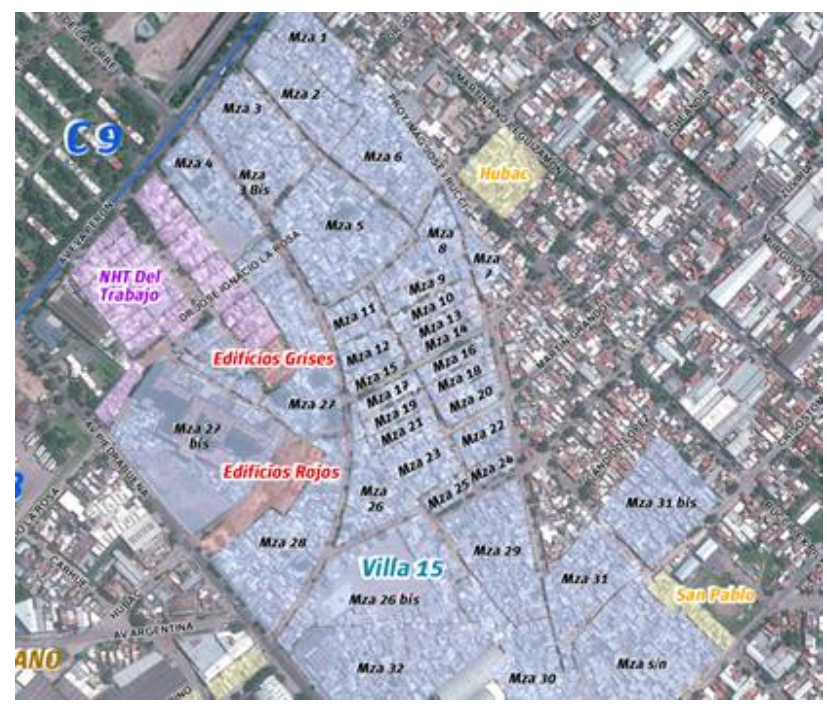

Figura 3: Ubicación obras Sueños Compartidos Villa 15-Ciudad Oculta. Fuente: intervención sobre imagen obtenida desde Google Earth con información de la Dirección General de Estadística y Censos, Ministerio de Hacienda (Brikman, 2017).

Si bien en los orígenes el proyecto contemplaba la completa urbanización de la villa, finalmente sólo se intervino en dos de las 37 manzanas que conforman Villa 15 y en ninguna de las manzanas del N.H.T. Av. del Trabajo - considerado parte del territorio de análisis-

En relación con la incidencia de la estructura institucional sobre las formas de gestión del programa en este territorio, el convenio inicial establecía como unidad ejecutora y de financiamiento al Gobierno Nacional (Ministerio de Planificación Federal, Inversión Pública y Servicios - Secretaría de Obras Públicas) en articulación con unidades ejecutoras locales, en este caso, el Instituto de la Vivienda de la Ciudad (IVC) y la Corporación Bs.As. Sur (CBAS). El desarrollo de la obra estaba a cargo de la Fundación Madres de Plaza de Mayo ${ }^{5}$ (Auditoría General de la Nación, 2013). Sin embargo, si bien la implementación del programa requería la articulación de estos tres actores, en los hechos concretos la articulación fundamental se dio entre el Gobierno Nacional y la Fundación.

Por otro lado y en relación con las características del territorio sobre el desarrollo de mecanismos de gestión del suelo, Villa 15 se asienta sobre terrenos que actualmente son propiedad del Gobierno de la Ciudad, el Gobierno Nacional y otros de propiedad privada. A lo largo de la historia diversas políticas (dotación de servicios, construcción de equipamiento, etc.) fueron frenadas por problemas de dominio de tierras. Particularmente estas dos manzanas se ubican en una de las zonas más emblemáticas del barrio, donde el Estado intervino históricamente. El suelo donde se ubica el Elefante Blanco y sus terrenos cercanos - donde se construyen las viviendas aquí analizadas - son cedidos por la Municipalidad de Bs.As. en 1935 a la Liga contra la Tuberculosis para la creación de un hospital. Frente al abandono del proyecto, en 1948 dichos terrenos son expropiados por el Gobierno Nacional a fin de concluir las obras. En 1978, se transfieren al Gobierno de la Ciudad. Luego en 2006, los predios se ceden mediante un convenio de uso a la FMPM. En 2011, el edificio y las obras pasaron a ser administradas por el Movimiento Evita hasta que a fines del 2012 por incumplimiento del proyecto, los terrenos vuelven a dominio del GCBA, específicamente el Ministerio de Desarrollo Social. 6

Los traspasos de dominio entre esferas de Gobierno y organizaciones sociales evidencian un proceso de gestión del suelo particular en Villa 15 , vinculado con las

\footnotetext{
${ }^{5}$ La asociación civil fue responsable de la construcción mediante Convenios Únicos de Colaboración y Transferencia y un Contrato de Obra Pública

${ }^{6}$ La información referida a la historia del Elefante Blanco se obtuvo mediante el documento de Acción de amparo en defensa de derechos colectivos, Defensoría de primera instancia CAyT №5 MPD CABA, presente en el Anexo de documentos jurídicos de la Revista del Ministerio de Defensa Pública (2016) "El caso Serra y la vida en el Elefante Blanco. No solo es el edificio, son las personas".
} 
características del territorio pero también al contexto político. Cuando el Programa inicia, el Gobierno de la Ciudad y Nacional poseían el mismo signo político, lo cual facilitó la implementación del programa. A la vez la Villa 15 históricamente posee una estructura organizativa vinculada al peronismo, que se traduce en el periodo de análisis, en nuevos referentes y organizaciones identificados al partido político gobernante (Brikman, 2017). Estas características pueden haber facilitado la implementación del programa por parte de una ONGs y una organización social, mediante la cesión de usos de tierra pública.
Asimismo, la localización de villa 15 en relación con el resto de la ciudad, como se mencionó previamente, pudo haber constituido un factor de atracción para el desarrollo de este programa en el barrio. La ubicación del asentamiento un una zona con menor atractivo para el sector inmobiliario que el resto de la ciudad y la histórica presencia del Estado en la producción de soluciones habitacionales localizadas en esta zona pueden pensarse como elementos que condicionaron la elección del territorio como zona de implementación (Tabla 2).

\section{Tabla 2}

Resultados según dimensiones de análisis en Ciudad Oculta - Villa 15

\begin{tabular}{|c|c|c|}
\hline \multicolumn{2}{|c|}{ Instrumentos de gestión del suelo } & \multirow{2}{*}{$\begin{array}{l}\text { Cesión de uso por parte del GCBA a la FMPDM } \\
\begin{array}{l}\text { Presencia de actores con alianzas políticas. Gobierno Nacional, GCBA, FMPDM, } \\
\text { organizaciones sociales y políticas de barrio }\end{array}\end{array}$} \\
\hline Características & Actores intervinientes & \\
\hline & Definición de destinatarios & Población Villa 15//Cooperativas de trabajo de habitantes del barrio en su mayoría \\
\hline \multirow{3}{*}{$\begin{array}{l}\text { Características } \\
\text { territoriales }\end{array}$} & Localización del barrio & $\begin{array}{l}\text { Urbanización in situ destinada a los habitantes del barrio. Se trata de un territorio ubicado } \\
\text { en las antiguas periferias de la ciudad, con bajo valor y atractivo para el mercados } \\
\text { inmobiliario }\end{array}$ \\
\hline & Propiedad del suelo & $\begin{array}{l}\text { Villa } 15 \text { se ubica en territorios de propiedad fiscal Nacional y provincial, y privados. La } \\
\text { zona en la que se construyó pertenecía al Estado Provincial facilitando la implementación } \\
\text { del proyecto. }\end{array}$ \\
\hline & $\begin{array}{l}\text { Escala Barrial y de } \\
\text { intervención }\end{array}$ & $\begin{array}{l}\text { Si bien la proyección era la urbanización completa de la villa, se concretaron } 48 \text { viviendas } \\
\text { finalizadas, } 96 \text { proyectadas en 1a etapa, correspondientes a dos manzanas de Villa } 15 \text { (que } \\
\text { cuenta con } 37 \text { manzanas) y ninguna del N.H.T. La escala de la intervención efectiva se } \\
\text { restringió a la zona donde la propiedad del suelo era exclusivamente del Estado de la } \\
\text { Ciudad de Buenos Aires }\end{array}$ \\
\hline
\end{tabular}

Fuente: Elaboración propia.

\section{El caso Barrio Padre Mugica.}

El complejo se construye bajo el programa Sueños Compartidos en el marco del Subprograma Federal de Urbanización de Villas y asentamientos precarios, mediante una operatoria específica junto a organizaciones de la sociedad civil -en este caso la Fundación Madres de Plaza de mayo-. El programa contemplaba inicialmente contratar como mano de obra para la construcción de las viviendas a los futuros habitantes, siendo un puntapié inicial para la organización local y comunitaria.

Sin embargo, la definición inicial imprecisa de los destinatarios de las viviendas del CUBPM generó obstáculos en el logro de este objetivo facilitando la adjudicación de las viviendas por parte del Poder Ejecutivo de la CABA por fuera de los destinatarios originales del programa. El conjunto urbano fue poblado por hogares relocalizados desde diversas villas $y$ asentamientos de la Ciudad por vías de judicialización. Otro pequeño grupo de destinatarios incluyó a un conjunto de hogares de la ex villa 19 Barrio INTA, ubicado en las proximidades del Conjunto.

En este sentido, si bien la selección del predio guardaba relación con el propósito de construir vivienda y hábitat adecuado destinado a habitantes de asentamientos informales que se encuentran a su alrededor, este propósito se vio desdibujado 
mediante los criterios de adjudicación. Como consecuencia, el caso del Barrio Padre Mugica terminó implicando desplazamientos de población de bajos ingresos hacia zonas con menores equipamientos (Figura 4), reproduciendo viejas tendencias de concentración de producción de vivienda social en los márgenes sur de la ciudad (Najman, 2018).

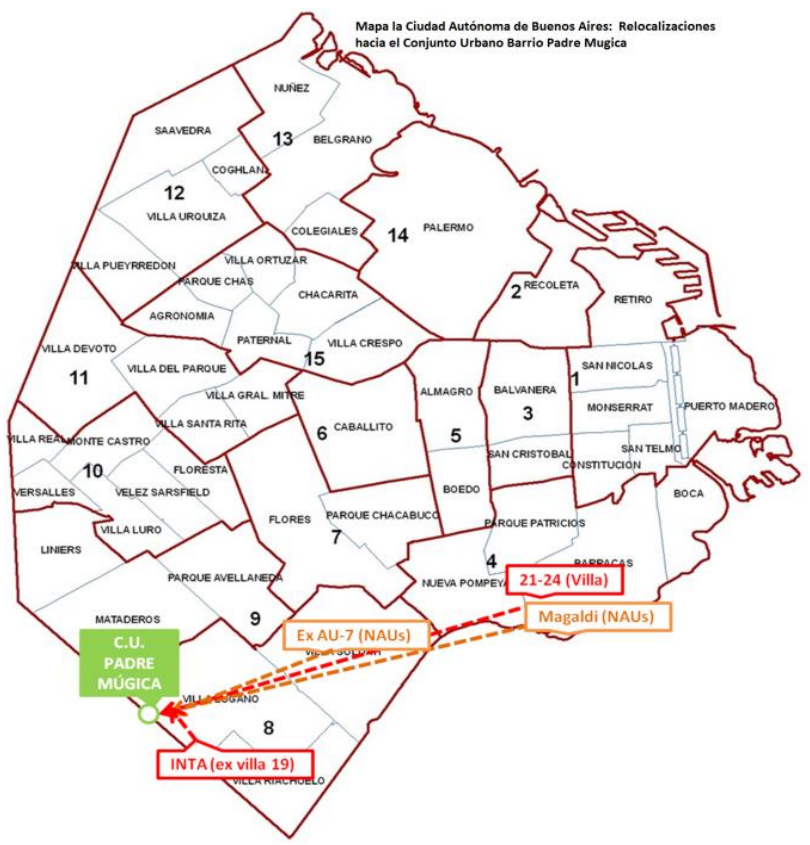

Figura 4: Mapa de la CABA. Relocalizaciones. Fuente: Elaboración propia.

La adjudicación guarda relación con las características de los mecanismos de gestión del suelo incorporados. La construcción del Conjunto se desarrolló sobre terrenos que habían sido declarados inmuebles de utilidad pública y sujetos a expropiación mediante la Ley 1987 del 2006. Esta Ley destinaba dichos terrenos al desarrollo del hábitat popular orientado a satisfacer la demanda de viviendas sociales de la totalidad de familias habitantes del asentamiento AU7 (marca naranja Figura 5). Este primer instrumento de gestión del suelo se articula en el año 2007 con la cesión de uso de un predio aledaño de propiedad del Estado Nacional al municipal, mientras su dominio continuó bajo la órbita del Estado Nacional (marca celeste Figura 5). Posteriormente se firma un convenio entre el Instituto de la Vivienda de la Ciudad y la Fundación Madres de Plaza de mayo, quien llevó a cabo la obra. De este modo, el programa Sueños
Compartidos comienza a desarrollarse mediante la operatoria especial del SUVAP. Las 220 viviendas pactadas inicialmente, fueron extendidas a 780 en el año 2008.

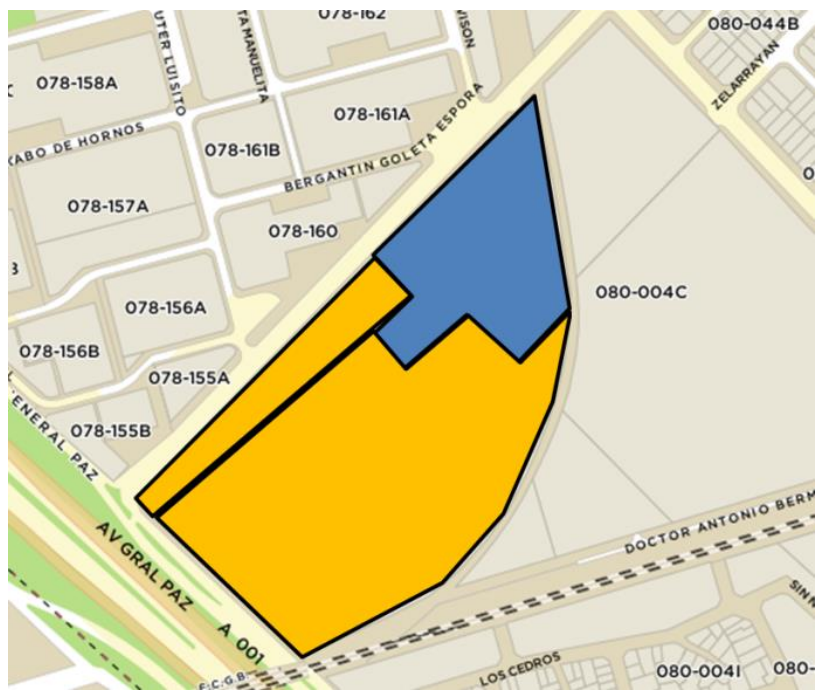

Figura 5: Dominio original de terrenos utilizados. Fuente: Elaboración propia.

La localización del proyecto estuvo vinculada a la necesidad del Estado de dar una solución habitacional urgente -bajo sentencia judicial- a los habitantes de Villa Cartón y a la disponibilidad de suelo en dicha zona. Luego, a partir de la intervención de la FMDP, en el marco del SUVAP, se resignifica el sentido la localización mediante la creación de un nuevo proyecto. En este sentido, el Programa Misión Sueños Compartidos se propuso generar un proceso de inclusión socio-urbana de los asentamientos informales de la zona, mediante la construcción de vivienda nueva. Tal como mencionamos, el Programa buscaba conservar los espacios de vida producidos popularmente garantizando un hábitat de calidad. Con la redefinición de los adjudicatarios, se desdibujó el rol que la localización del suelo representaba en el programa. Las redefiniciones impulsadas por las urgencias por resolver una serie de litigios que comprometían al Gobierno de la Ciudad empujaron hacia la continuidad de los abordajes históricos de las políticas de vivienda social. Lejos de dotar de mayor calidad de hábitat a un territorio producido informalmente, el programa terminó generando un nuevo barrio con equipamientos insuficientes para las necesidades de quienes lo habitan, duplicando escenarios de desigualdad. 
Actualmente, el CUBPM posee 600 viviendas habitadas, 120 próximas a ser adjudicadas y 60 cuya construcción quedó paralizada. Los hogares que allí residen no cuentan aún con escrituras de sus viviendas ni conocen los plazos formales en los que podrán iniciar el pago de las cuotas para acceder a la propiedad formal de las mismas. Las autoridades intervinientes atribuyen parte de esta demora en la escrituración a los conflictos entre las distintas esferas estatales que utilizan a la propiedad fiscal del suelo donde se desarrolló la intervención como elementos de la disputa política (Tabla 3).

\section{Tabla 3}

Resultado según dimensiones de análisis en Barrio Padre Mugica

\begin{tabular}{|c|c|c|}
\hline Instrumentos de gestión del suelo & & $\begin{array}{l}\text { Cesión de uso por parte del Gob. Nacional al GCBA junto a expropiación } \\
\text { de suelo privado }\end{array}$ \\
\hline \multirow{3}{*}{ Características institucionales } & Actores intervinientes & $\begin{array}{l}\text { Cambio de signo político de los distintos actores en el curso de la } \\
\text { implementación: Gobierno Nacional, GCBA, FMPDM, Asoc. Civil Esperanzas } \\
\text { de un cambio, ACUMAR, Poder Judicial. }\end{array}$ \\
\hline & Definición de destinatarios & $\begin{array}{l}\text { Relocalización de distintos asentamientos de la ciudad: Ex AU7, } \\
\text { asentamiento Magaldi, Villa 21-24// Cooperativas de trabajo integradas } \\
\text { por vecinos de Ex AU7, Villa 15, INTA y Bermejo. }\end{array}$ \\
\hline & Localización del barrio & $\begin{array}{l}\text { Relocalización en barrio ubicado en borde de CABA - antiguas periferias-, } \\
\text { implicando el empeoramiento de la localización relativa de los } \\
\text { destinatarios. La selección de la ubicación en la cual se construyó puede } \\
\text { guardar relación con el bajo valor del suelo privado que fue expropiado y a } \\
\text { la concentración de intervenciones estatales en esta zona de la ciudad. }\end{array}$ \\
\hline \multicolumn{3}{|l|}{ Características territoriales } \\
\hline & Propiedad del suelo & Suelo fiscal del Estado Nacional y de propiedad privada expropiada. \\
\hline & Escala barrial y de intervención & $\begin{array}{l}\text { La obra original proyectaba } 780 \text { viviendas y espacios comunitarios como } \\
\text { escuelas, salitas de salud, etc. Se concretó únicamente la construcción de } \\
720 \text { viviendas. }\end{array}$ \\
\hline
\end{tabular}

Fuente: Elaboración propia. 


\section{EI SUVAP en Avellaneda.}

Villa Tranquila y Cardales se ubican en el Municipio de Avellaneda, localizado en la primera conurbación del Gran Buenos Aires; al sur de la Ciudad y teniendo como límite el Riachuelo. La historia del Municipio está vinculada con el Puerto y su origen industrial, así como con la cercanía con la Capital. Tuvo un poblamiento antiguo, protagonizado por trabajadores guiados por las fuentes laborales y la cercanía con la metrópolis (Figura 6).

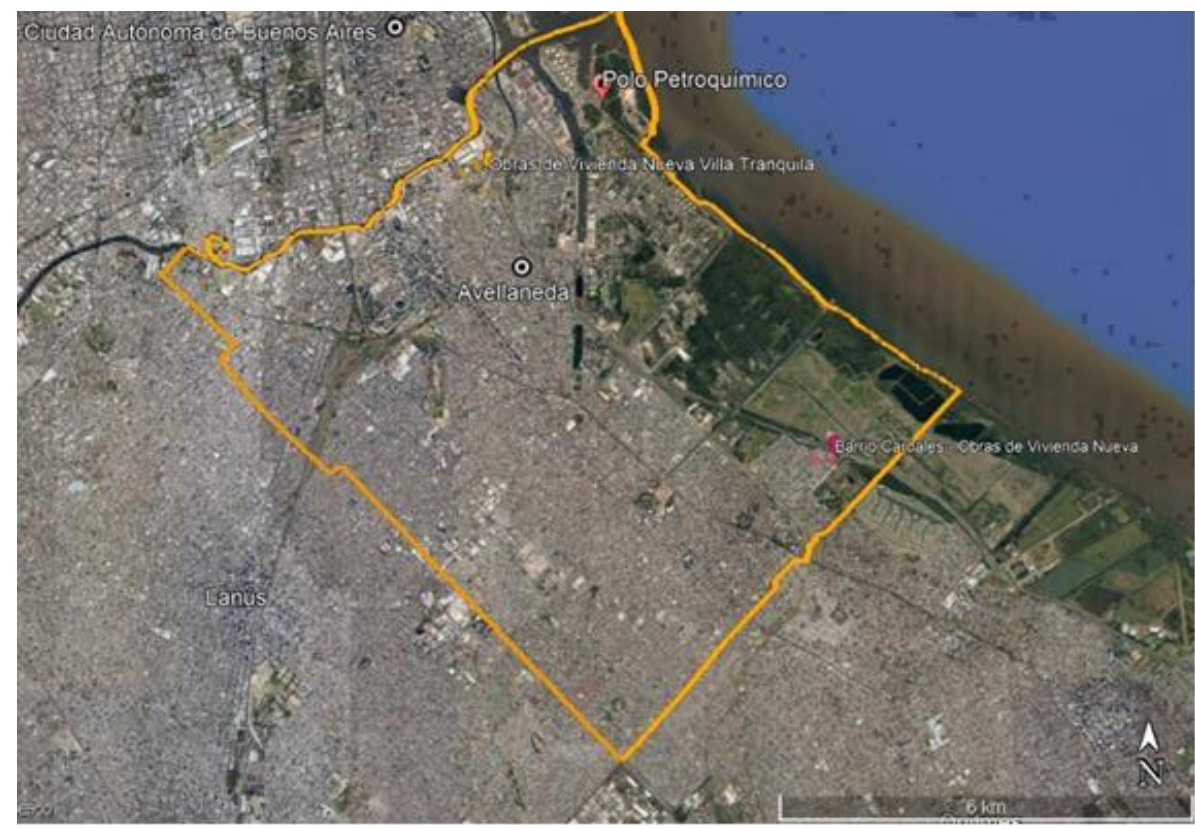

Figura 6: localización de casos de estudio de Avellaneda. Fuente: intervención sobre imagen obtenida desde Google Earth.

A diferencia de otros municipios de la Provincia de Buenos Aires, Avellaneda tiene una trama urbana antigua y en mayor medida consolidada. Esto dificultó inicialmente la implementación de los Programas Federales de Construcción de Vivienda, dado que existían escasos predios libres, por lo que el lanzamiento del SUVAP resultó un alivio para la ejecución de la política habitacional. Esta modalidad se combinó con la refuncionalización de predios industriales que, tras la década de 1990, habían quedado en desuso. En este sentido, es posible afirmar que las características propias del territorio han moldeado el modo en que se implementó el programa en este municipio.

Así, Avellaneda pone en marcha un ciclo protagonizado por la política habitacional, que Olejarczyk (2014) denominará "máquina de hacer proyectos". El dinamismo de esta etapa tiene un correlato en su ejecución; e hizo de Avellaneda el Municipio del Primer Cordón con mayor cantidad de soluciones habitacionales efectivizadas (5.346 viviendas nuevas y 3.350 mejoramientos). La política principal fue el SUVAP, pero las herramientas de gestión fueron múltiples.

\section{El caso de Villa Tranquila}

Villa Tranquila, es uno de los principales barrios informales de Avellaneda, debido al amplio número de habitantes, aproximadamente 7000 , y a su localización central pues sus principales vías de acceso se ubican a 600 metros del puente Pueyrredón y a 30 minutos del centro de la Ciudad de Buenos Aires. A la vez, es uno de los barrios informales más antiguos del municipio, su poblamiento estuvo vinculado con las fuentes laborales que generaban el antiguo puerto, las curtiembres y las múltiples industrias que se asentaron en el territorio. Esta también le dio una yuxtaposición residencial e industrial a la zona, que deterioró su calidad ambiental. 
En el año 2005, Avellaneda subscribió al primer convenio para la implementación del SUVAP en el Conurbano Bonaerense. Villa Tranquila fue el territorio de intervención en su plan de urbanización, esta política se combinó con otros programas e instrumentos de gestión preexistentes en el territorio. El Programa de Mejoramiento Barrial (PROMEBA) había comenzado a implementarse en Villa Tranquila poco tiempo antes, y ello permitió contar con múltiples activos (censo barrial reciente, equipo técnico e información catastral). Además, antes de la llegada de los PF, el gobierno local había trabajado en la recuperación de ciertos terrenos que comprenden el área de Villa Tranquila y predios adyacentes. En este marco, se insertó la donación por parte de la empresa Unilever de un terreno aledaño, que habilitó suelo disponible para el inicio del proceso de urbanización, que luego se continuó mediante esponjamiento (Figura7). En este caso, la donación de los predios de Unilever dio cumplimiento al requerimiento central para la implementación del SUVAP y el PROMEBA: contar con un predio regularizado o posible de serlo para iniciar las obras. La adquisición de suelo a partir de donaciones puede ser pensado como un instrumento discrecional que habilita a los propietarios de terrenos con deudas de tributos provinciales a ceder las tierras al municipio, a cambio de evitar su pago, Ley provincial 11.622 (Del Río y Duarte, 2012).

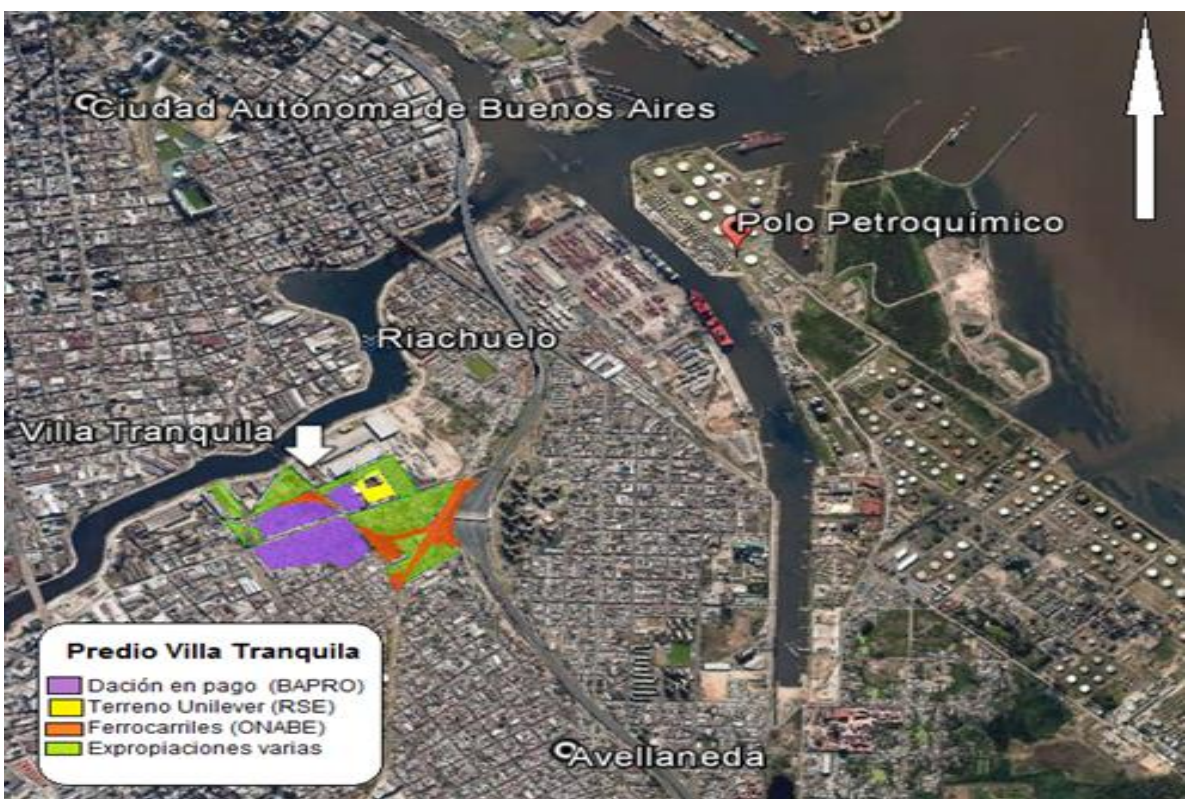

Figura 7: Dominio original de terrenos utilizados y modos de gestión. Fuente: Elaboración propia a partir de entrevistas en profundidad con funcionarios de la Secretaría de Obras y Servicios Públicos, Avellaneda, sobre imagen obtenida desde Google Earth.

Al predio de Unilever se le suma la gestión de suelo de otros terrenos para la ejecución del programa: los terrenos del Banco Provincia (BAPRO), el traspaso de los terrenos nacionales de origen Ferroviario $^{7}$ y diversos predios privados que se intentaron comprar y/o expropiar. En primer lugar, el predio del BAPRO fue cedido al Municipio de Avellaneda en dación de pago, a cuenta de deudas que tenía por impuestos municipales. En segundo lugar, se comenzó con los trámites de

\footnotetext{
${ }^{7}$ En ese momento estaban en posesión de la ONABE (Órgano Nacional de Administración de Bienes del Estado), Órgano disuelto en 2012, para crearse la Agencia de Administración de Bienes del Estado.
}

traspaso de terrenos del Estado Nacional, en su mayoría remanentes ferroviarios, a la órbita municipal. Esta modalidad de gestión del suelo característica de terrenos fiscales, lejos de constituir una opción accesible, despertó múltiples obstáculos producto de las burocracias interestatales. Por lo que, podemos señalar que en el municipio de Avellaneda la presencia de tierra fiscal no se tradujo en una facilidad para la construcción de vivienda social.

Finalmente, el municipio debió avanzar en la gestión de suelo perteneciente a privados. Algunos ocupados por la población de Villa Tranquila y un conjunto de predios 
utilizados para actividades industriales o de logística que se encontraban rodeados por el crecimiento del barrio. El Gobierno Municipal, como primera medida, ofreció comprarlos, lo cual despertó diversas reacciones entre los propietarios: tasaciones muy elevadas ante la expectativa del proyecto de urbanización, oposiciones a la venta, desacuerdos entre los poseedores de un mismo predio, etcétera. Ante ello, la estrategia dirimida por el gobierno local fue iniciar un proceso de expropiación a fin de presionar a la venta y/o disminuir el precio asignado por el mercado inmobiliario. Como última medida, procedió a adquirir los predios vía judicialización. Esta última estrategia, fue la menos priorizada debido a los prolongados tiempos que impone; por lo que, en la mayoría de los casos, se utilizó únicamente como herramienta de presión.

Hasta aquí se observa que el conjunto heterogéneo de herramientas de gestión del suelo que el municipio puso en juego influyó en la viabilidad de los proyectos.
No obstante, los tiempos y las características propias de la lógica estatal dificultaron el proceso.

El Plan de Urbanización iniciado en el 2005, tuvo financiamiento del Estado Nacional para la construcción de 701 viviendas nuevas y 300 mejoramientos, organizado en distintas etapas. En paralelo, se proyectaba la apertura de una nueva vía de acceso principal, de varias calles internas al barrio y la construcción de nuevas redes de infraestructura y servicios públicos. En relación con la construcción de vivienda nueva, si bien se inició con la construcción de 183 viviendas en el predio de Unilever que habilitó el esponjamiento y liberación del predio lindero (cedidos por BAPRO) para continuar con las obras, no todas las obras de vivienda nueva se terminaron (sombreado en naranja las viviendas entregadas al 2015). Muchos proyectos fueron modificados o simplemente se paralizaron (Figura 8, sombreado verde), frenando otras instancias del Plan de Urbanización.

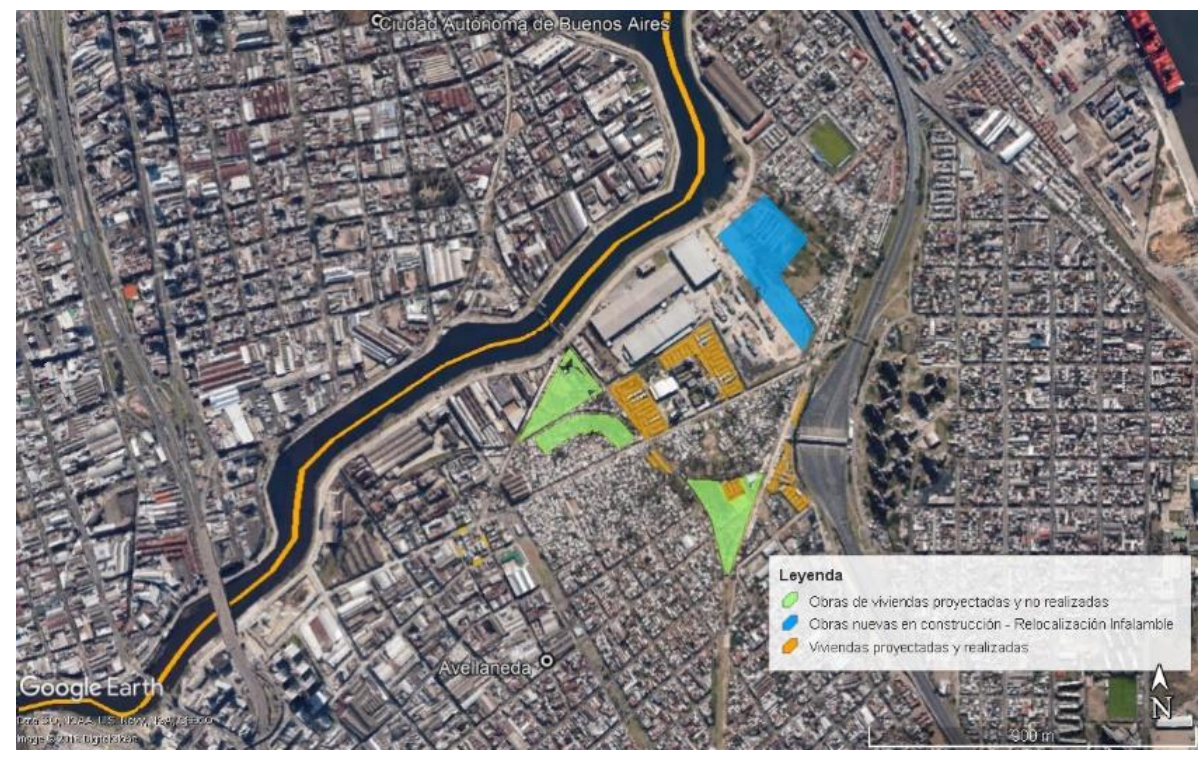

Figura 8: Intervenciones en el proceso de Urbanización de Villa Tranquila. Fuente: intervención sobre imagen obtenida desde Google Earth. 
Más recientemente, y por fuera del Plan de Urbanización del barrio, se llevó a cabo en el territorio un plan de 440 viviendas que se ubican al este del predio de Unilever (Figura 8, sombreado celeste) destinadas a la relocalización de población de otro asentamiento - Villa
Inflamable-. En el marco de conflictos judiciales, el Gobierno Municipal modificó el destinatario de la política durante su implementación en respuesta a urgencias de gestión (Tabla 4).

\section{Tabla 4}

Resultados según dimensiones de análisis en Villa Tranquila

\section{Instrumentos de gestión del suelo}

\begin{tabular}{|c|c|c|}
\hline & & expropiación \\
\hline \multirow{3}{*}{ Características institucionales } & Actores intervinientes & $\begin{array}{l}\text { Gobierno Nacional, Gobierno Municipal de Avellaneda, propietarios } \\
\text { privados, empresas constructoras, ACUMAR }\end{array}$ \\
\hline & Definición de destinatarios & Población Villa Tranquila y relocalizados de la Causa Mendoza \\
\hline & Localización del barrio & $\begin{array}{l}\text { Barrio ubicado en zona central de Avellaneda. Principalmente urbanización } \\
\text { in situ y en menor medida, relocalización }\end{array}$ \\
\hline \multirow[t]{2}{*}{ Características territoriales } & Propiedad del suelo & $\begin{array}{l}\text { Suelo fiscal del Estado Nacional (terrenos del Ferrocarril y Vialidad), } \\
\text { Municipio de Avellaneda y de privados (Unilever, Exolgan y otros) }\end{array}$ \\
\hline & Escala Barrial y de intervención & $\begin{array}{l}\text { Se proyectaba una reurbanización integral con } 811 \text { viviendas construidas, } \\
\text { se entregan } 596 \text { viviendas y se realiza apertura de calles y dotación de } \\
\text { nuevos espacios recreativos y de servicios públicos }\end{array}$ \\
\hline
\end{tabular}
Traspaso de terrenos fiscales nacionales al municipio, compra a privados, expropiación

Gobierno Nacional, Gobierno Municipal de Avellaneda, propietarios se entregan 596 viviendas y se realiza apertura de calles y dotación de
Dación de privados como parte de pago de deudas, Donación (RSE),

Fuente: Elaboración propia.

las obras del Programa Federal, que desafectó parte de la Reserva Ecológica, y habilitó las obras de vivienda.

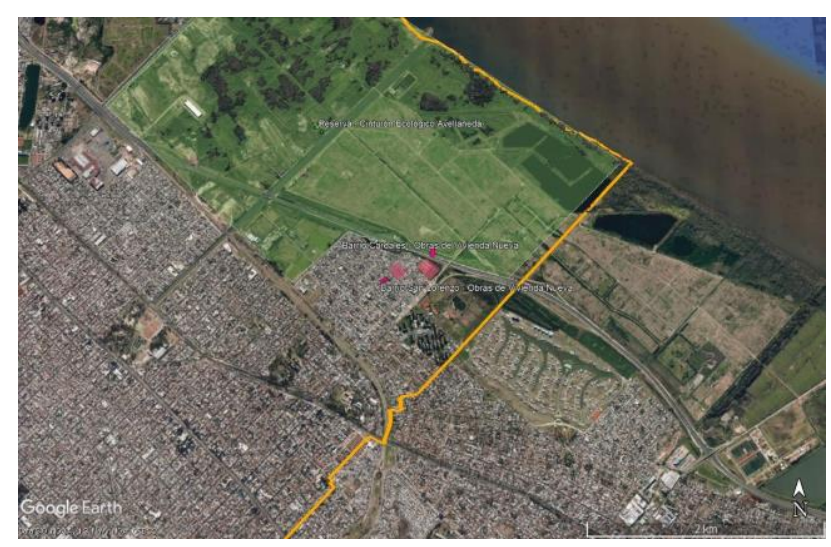

Figura 9: Predio Cardales, Avellaneda, 2017. Nota: intervención sobre imagen obtenida desde Google Earth.

A diferencia de Villa Tranquila, Los Cardales no se localiza en la centralidad del municipio, sino al borde de la trama urbana. Esta localización posee una baja oferta de servicios y equipamientos, es decir, menores externalidades urbanas para sus futuros pobladores. A la vez, otro elemento a considerar es que Cardales se ubica 
en la primera cota de inundación, con graves consecuencias ambientales. Ambos factores distintivos en torno a la ubicación del nuevo barrio parecen guardar relación con la disponibilidad, valor del suelo y el cálculo de rentabilidad de la empresa oferente (Tabla 5 ).

\section{Tabla 5}

Resultados según dimensiones de análisis en Los Cardales

Instrumentos de gestión del suelo
Actores intervinientes

Definición de destinatarios

Localización del barrio

Propiedad del suelo

Escala Barrial y de intervención
Tierra y Proyecto Urbano (TPU): terrenos propuestos por empresa constructora ganadora de licitación

Gobierno Nacional, Gobierno Municipal de Avellaneda, empresa privada ganadora de licitación

Relocalizados: s/d

Barrio ubicado en zona periférica del Municipio de Avellaneda. Relocalizaciones sin datos precisos del lugar del origen de los destinatarios.

Privado

El proyecto original contempla 158 viviendas. Actualmente hay 66 viviendas finalizadas y 92 en ejecución
Fuente: Elaboración propia.

\section{Conclusiones}

A lo largo de este artículo hemos reflexionado acerca del lugar que ocupó el suelo en el diseño de soluciones estatales para la urbanización de asentamientos informales que se insertan en la política habitacional delineada en Argentina tras la salida de la crisis socioeconómica del 2001-2002. En ese marco, identificamos algunos rasgos que caracterizaron las experiencias de gestión del suelo presentes en los cuatro casos de estudio seleccionados.

En primer lugar, reconstruimos los diferentes instrumentos y tipos de gestión que se han desarrollado con el propósito de acceder al suelo necesario para la construcción de vivienda nueva. En este sentido, identificamos diversas estrategias de gestión del suelo, que en muchos casos se han combinado entre sí: cesión de uso del suelo desde una esfera de Gobierno (nación) a otra (municipio) sin involucrar cesión de propiedad del mismo, cesión de propiedad fiscal nacional a municipal, expropiación a privados, donación de tierras privadas al Estado Municipal, dación en pago por deudas fiscales, compra directa por parte de la empresa constructora (modalidad TPU), cesión de usos de terrenos fiscales a ONGs o asociaciones de la sociedad civil y compra de terrenos privados por parte del Estado.
Es preciso resaltar que en muchos de estos casos, el Estado avanzó en las obras de urbanización aún sin contar con el dominio del suelo en donde se emplazaban. En este sentido el Subprograma habilitó un canal de ejecución con límites más difusos en lo que respecta a la propiedad del suelo. Puede pensarse que este mecanismo fue posibilitado, en algunos casos, gracias a la afinidad política entre las instancias de gobierno ejecutoras y aquellas responsables del financiamiento. Este canal, que permitió superar el desfasaje que se producía respecto a las temporalidades de la política y las temporalidades de la gestión del suelo, terminó reproduciendo en muchos casos la situación de informalidad en la tenencia de las viviendas que caracterizaba previamente a la población destinataria.

Asimismo, hemos observado que algunas de las características de los barrios donde la intervención se ha realizado, pudieron haber funcionado como atractivos para ser elegidos. En primer lugar, los asentamientos localizados sobre tierras fiscales nacionales -como es el caso de Villa Tranquila y Villa 15- implicaban una facilidad para el municipio, debido en gran parte a la afinidad política entre ambas esferas de gobierno. La firma de los convenios del SUVAP en los cuatro casos analizados, se han realizado en un contexto político en el 
que tanto los gobiernos municipales como el nacional eran parte del mismo partido gobernante. A partir del año 2008, la Ciudad de Buenos Aires pasa a ser gobernada por el PRO (Propuesta Republicana), inaugurando una nueva etapa en la que los dos niveles de gobierno se encuentran enfrentados políticamente. Por el contrario, el Municipio de Avellaneda continuó caracterizándose por su afinidad política con el Gobierno Nacional hasta el año 2015, cuando el PRO accede al Gobierno Nacional.

Por otro lado, la localización relativa constituye otra característica que ha influido en la elección de los barrios a intervenir. El barrio de Villa Lugano, donde se localizan Villa 15 y CUBPM, ha sido históricamente un territorio destinatario de políticas de construcción de vivienda y actualmente continúa representando una de las áreas de menor valor de mercado de la ciudad. En el caso de Villa 15 , la construcción de vivienda se ubica dentro de un territorio producido históricamente por sus habitantes. Por el contrario, la elección del nuevo barrio Padre Mugica, se relaciona con la capacidad del Estado Municipal de expropiar terrenos colindantes a suelo fiscal antes que con la ubicación de sus destinatarios.

La localización del nuevo barrio Los Cardales, presenta también un bajo valor de mercado dentro del Municipio de Avellaneda, asociado en gran medida a su ubicación periférica, a su realidad ambiental y a las bajas externalidades urbanas que representa. Por el contrario, Villa Tranquila se localiza en una zona céntrica, habilitando un conjunto de externalidades positivas. Por lo que, pese a ser un territorio históricamente degradado, donde el hábitat informal se yuxtapone con usos industriales contaminantes, y predios anegables, resulta un predio atractivo para rehabilitar por medio de la intervención estatal. Lo anterior, es reforzado por la existencia de lotes en desuso en los alrededores del barrio, que permitirían un proceso de esponjamiento y también de intercambio interesante para los privados de la zona.
Los cuatro casos de estudio ejemplifican dos opciones de implementación de los programas de urbanización según su localización: aquellos realizados en territorios previamente habitados por los destinatarios y aquellos realizados en "suelo disponible" donde la población destinataria atravesó procesos de relocalización. Las soluciones habitacionales definitivas brindadas por el Estado se han emplazado principalmente sobre suelo de bajo valor de mercado y cuya adquisición por el Estado, mediante diversas estrategias de gestión, resultaba factible.

Por último, en los distintos casos de análisis se configura un entramado actoral en torno al rol del Estado (tanto nacional como municipal). El desembarco de la política en los territorios fue facilitado mediante la relación favorable con otros actores no estatales (privados, ONGs, organizaciones sociales). Asimismo, la población destinataria también formó parte de este entramado de actores intervinientes, aunque en diversas medidas. En los dos proyectos de CABA, los destinatarios ocuparon un rol central durante la construcción, al integrar las cuadrillas de construcción de las viviendas. EI lugar asignado a los destinatarios por el Programa Sueños Compartidos parecía romper las lógicas de las políticas de vivienda tradicionales. Sin embargo, la interrupción del programa desplazó a los destinatarios de la ejecución de la política y construcción de sus viviendas.

Analizar las estrategias de gestión del suelo desplegadas por los actores estatales, nos permitió iluminar una dimensión de las políticas habitacionales que, si bien no es contemplada en el diseño de estas, constituye un factor estructural y posibilitante. Si las políticas habitacionales tienen como propósito transformar las condiciones de vida de los destinatarios, nos preguntamos en qué medida las estrategias sobre las que éstas se apoyan han logrado transformar el lugar que ocupan estas poblaciones en la ciudad [B] 


\section{Referencias}

Auditoria General de la Nación (2013). Informe de auditoría fundación madres de plaza de mayo: mision sueños compartidos - gestión transferencias. Autor.

Blanco, A., Carrión, D., Fretes Cibils, V., Hurtado Tarazona, A., Mendive, C., Muñoz Miranda, A. y Sandroni, P. (2016). Expandiendo el uso de la valorización del suelo: La captura de plusvalías en América Latina y el Caribe, Washington: BID. Disponible en https://publications.iadb.org/publications/spanish/do cument/Expandiendo-el-uso-de-lavalorizaci\%C3\%B3n-del-suelo-La-captura-deplusval\%C3\%ADas-en-Am\%C3\%A9rica-Latina-y-elCaribe.pdf

Bois Morales, G. (2008). Segregación y modelo habitacional en grandes conjuntos de vivienda en México. En Cordera (comps), Pobreza, desigualdad y exclusión social en la ciudad del siglo XXI. México: Siglo XXI.

Brikman, D. (2017). Formas de intervención en el territorio, políticas de urbanización de villas $y$ entramado de actores. El caso de ciudad oculta (Tesis de Maestría). Universidad de Buenos Aires, Buenos Aires.

Calderón, J. (2015). Programas de vivienda social nueva y mercados de suelo urbano en el Perú. EURE (Santiago), 41(122), 27-47. http://dx.doi.org/10.4067/s0250$\underline{71612015000100002}$

Chiara, C., Virgilio, M. M. D., y Aramburu, F. (2017). Los planes federales de vivienda en el área metropolitana de Buenos Aires. URBANA: Revista Eletrônica Do Centro Interdisciplinar de Estudos Sobre a Cidade, 9(1), 70. https://doi.org/10.20396/urbana.v9i1.8646308

Clichevsky, N. (1999). Tierra Vacante en Ciudades Latinoamericanas. Situación Actual y Propuestas para su Utilización. El Caso de Buenos Aires, Argentina Informe de Investigación. Lincoln Institute of Land Policy. Buenos Aires.
Clichevsky, N. (2003). Pobreza y Acceso al Suelo Urbano: las Políticas de Regularización en América Latina. En CEPAL-AECI (Ed.), Curso Pobreza y Precariedad Urbana: Estrategias y Programas para Centroamérica y el Caribe (pp. 1-26). Antigua, Guatemala.

Di Virgilio, M.M.; Gil, A., Ostuni, F., Perea, C. y Vitale, P. (2011). Los Barrios de Villa Lugano y Villa Soldati, en Gil, A., Cosacov, N., Di Virgilio, M., Gil, M. L., Guevara, T., Imori, M. y Ramos, J. M. Barrios al sur: Villa Lugano, Villa Riachuelo, Mataderos, Parque Patricios y Villa Soldati a través del tiempo. Documentos de Trabajo (Universidad de Buenos Aires. Facultad de Ciencias Sociales), 56(1), 9-39. Disponible en http://lanic.utexas.edu/project/laoap/iigg/dt56.pdf

Cuenya, B. (2016). La política urbana frente a la mercantilización y elitización de la ciudad: algunas reflexiones y referencias a la situación argentina. Cuaderno Urbano, 21(21). 167-194. Disponible en https://dialnet.unirioja.es/descarga/articulo/5962306 .pdf

Del Río, J.P. y Duarte, J.I. (2012). La gestión del suelo y la distribución de la ciudad. Una articulación compleja para la política habitacional en el Conurbano Bonaerense. En Cristina Cravino (comps.), Construyendo Barrios. Transformaciones socioterritoriales a partir de los Programas Federales de Vivienda en el Área Metropolitana de buenos Aires (2004-2009) (pp. 42-77). Buenos Aires: CICCUS,

Fernandes, E. (2008). Consideraciones generales sobre las políticas públicas de regularización de asentamientos informales en América Latina. EURE (Santiago), 34(102). http://dx.doi.org/10.4067/S0250$\underline{71612008000200002}$

Hardoy, J. E. (1970). Políticas de urbanización y reforma urbana en América Latina. Buenos Aires: Instituto Torcuato Di Tella.

Ministerio Público de la Defensa Pública (2016). Anexo Documentos juridicos. Revista institicional de la Defensa Pública 6(8), 211-301. https://www.mpdefensa.gob.ar/publicaciones/revista -institucional-ndeg-8 
Najman, M. A. (2018) Construcción de vivienda social:¿i Motor para la inclusión? Impactos sobre el territorio y las estructuras de oportunidades de sus habitantes (Tesis de Maestría). Buenos Aires: FLACSO. Sede Académica Argentina

Olejarczyk, R. (2014). Tensiones en las versiones de una política pública: los Programas Federales de Construcción de Vivienda en Avellaneda (Tesis de Maestría). Buenos Aires: FLACSO. Sede Académica Argentina

Ostuni, F. (2007). Del FONAVI al Federal: Transformacionales socio-urbanas y respuestas estatales. Algunas reflexiones sobre la política habitacional. Buenos Aires: Centro de Documentación en Políticas Sociales. Subsecretaría de Gestión Social y Comunitaria. Buenos Aires, Ministerio de DDHH y Soc. GBA.

Ostuni, F. (2012). Aproximaciones a una no implementación. El Programa Federal de Viviendas en la Ciudad de Bs.As. En Cravino, M.C. (Ed.) Construyendo Barrios. Transformaciones territoriales a partir de los Programas Federales de Vivienda en el Área Metropolitana de Bs.As. (2004-2009) (pp. 87107). Buenos Aires: Espacio.
Pírez, P. (2014). La mercantilización de la urbanización. A propósito de los "conjuntos urbanos" en México. Estudios Demográficos y Urbanos, 29(3), 481. http://dx.doi.org/10.24201/edu.v29i3.1469

Renard, V. (2000). Planificación urbana y mercados de suelo urbano. Un padrón de intervenciones públicas. En Iracheta Cenecorta, Alfonso y Smolka Martim, Los pobres de la ciudad y la tierra (pp. 43-57). México: El Colegio Mexiquense AC, Lincoln Institute of Land Policy,

Rodríguez, A. y Sugranyes, A. (2005). Los con techo: un desafío para la política de vivienda social. Santiago de Chile: Ediciones SUR.

Sartori, G. (1994). Comparación y método comparativo. En Sartori G. y Morlino L., La comparación en las ciencias sociales (pp. 29-50). Madrid: Alianza Editorial.

Yujnosvky, O. (1984). Claves políticas del problema habitacional argentino 1955-1981. Buenos Aires: Grupo Editor Latinoamericano. 